\title{
Complication of Fiberoptic Bronchoscopy and Its Implementation for Special Conditions
}

\author{
Muhammad Miftahussurur ${ }^{1}$, Muhammad Yusuf Wibisono ${ }^{2}$ \\ ${ }^{I}$ Department of Internal Disease, Faculty of Medicine Universitas Airlangga, Dr. Soetomo General Hospital, Jl. Prof. \\ Moestopo 47 Surabaya 60132, Indonesia \\ ${ }^{2}$ Department of Pulmonology and Respiratory Medicine, Faculty of Medicine Universitas Airlangga, Dr. Soetomo General \\ Hospital, Jl. Prof. Moestopo 47 Surabaya 60132, Indonesia \\ miphto@yahoo.com,apji@fk.unair.ac.id
}

Keywords: Asthma, COPD, Fiberoptic Bronchoscopy, FOB Complications, Pulmonary Disease Therapy.

Abstract: $\quad$ Fiberoptic bronchoscopy (FOB) has been widely used for diagnosis and therapy for pulmonology and respiratory diseases. FOB is a safe procedure with a low complication and mortality rate (0.5-6.8\%). However, there are several complications to be considered. These complications occur during premedication (anticholinergic and local anesthesia) and sedation, during FOB (hypoxia, arrythmia and bleeding) and FOB with special conditions, i.e. after myocardial infarction, asthma, COPD, elderly, children, ICU, increased intracranial pressure and pregnancy.

\section{INTRODUCTION}

Since first introduced by Shigeto Ikeda in 1969 , fibrotic bronchoscopy has been widely used for diagnoses and therapy of pulmonology and respiratory diseases. FOB is a safe procedure with low complication and mortality rates, ranging between $0.5-6.8 \%$ depending on the type of management (Stolz et al., 2007).

Table 1: FOB Indication.

\begin{tabular}{|c|c|}
\hline \multicolumn{2}{|c|}{ Indication of FOB diagnoses and therapy. } \\
\hline 1. & Hemoptysis investigation \\
\hline 2. & $\begin{array}{l}\text { Persistent atelectasis or pneumonia in } \\
\text { the chest X-ray }\end{array}$ \\
\hline 3. & Stridor or localized wheezing \\
\hline 4. & $\begin{array}{l}\text { Unexplained unilateral phrenic } \\
\text { paralysis }\end{array}$ \\
\hline 5. & $\begin{array}{l}\text { Unexplained superior cava vein } \\
\text { syndrome or vocal cord paralysis }\end{array}$ \\
\hline 6. & $\begin{array}{l}\text { Smear cytology positive or suspicious } \\
\text { for malignancy }\end{array}$ \\
\hline 7. & Lung cancer staging \\
\hline 8. & $\begin{array}{l}\text { Airway injury due to toxic inhaled } \\
\text { substances }\end{array}$ \\
\hline 9. & $\begin{array}{l}\text { Airway breakup suspicion after } \\
\text { thoracic trauma }\end{array}$ \\
\hline 10. & Bronchopleural fistula study \\
\hline 11. & $\begin{array}{l}\text { Follow up in lung and heart-lung } \\
\text { transplantation }\end{array}$ \\
\hline
\end{tabular}

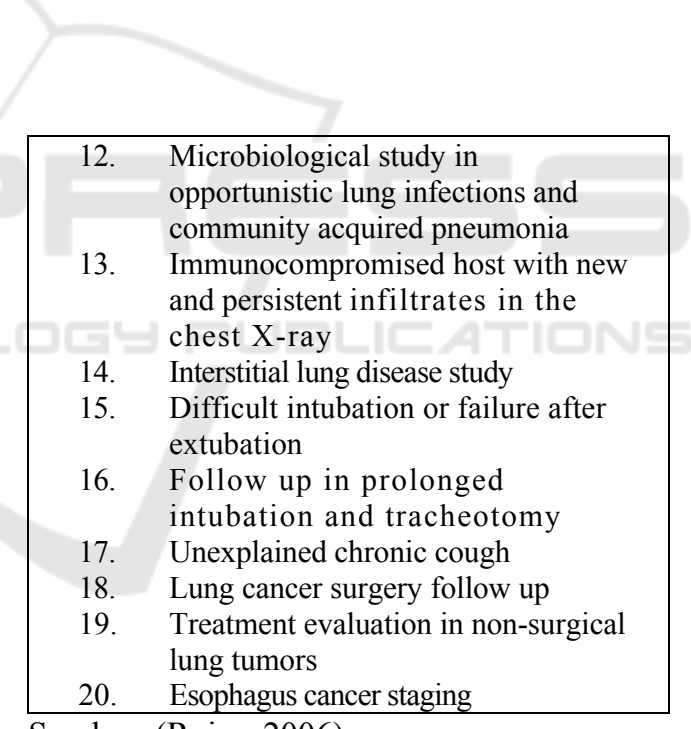

Sumber: (Rojas, 2006)

However, there are several complications to be aware of. These complications occur due to premedications and local anesthesia, due to management during FOB (hypoxia, arrythmia, bleeding, pneumothorax and infection) and FOB in special conditions, i.e. after myocardial infarction, asthma, COPD, elderly, children, ICU, increased intracranial pressure (ICP) and pregnancy (Veaudor et al., 2017; Stolz et al., 2007). Therefore, it is necessary to discuss the possibility of FOB complication occurrence in order to decrease the risk of complications. 


\section{FOB COMPLICATONS}

\subsection{Due to Premedications}

Anticholinergic atropine and glycopyrrolate have been generally used as FOB premedications to decrease bronchus secretions, vagal activity suppression and reflex bronchoconstriction as well as bradycardia. Premedication using atropine is reported to decrease the need for lignocaine anesthesia and reduce the risk of bronchoconstriction due to local anesthesia which is significant for patients with asthma (Veaudor et al., 2017). Atropine has side-effects of tachyarrhythmia, urine retention, blurred vision, glaucoma precipitation and dry mouth. Due to these sideeffects, atropine is not given routinely (Cowl et al., 2000).

Sedation is given to increase patients' comfort in order for FOB to run more easily and fast, if possible. Midazolam is benzodiazepine that is soluble in water with an elimination half-life of two hours. Generally, $0.07 \mathrm{mg} / \mathrm{kg}$ of midazolam is given prior to FOB. To increase adequate tolerance to FOB and amnesia induction, the doses of midazolam $(0.07-0.67 \mathrm{mg} / \mathrm{kg})$ are given gradually. Adequate sedation and amnesia can be achieved by giving a small initial dose of $2 \mathrm{mg}$, followed by $1 \mathrm{mg} / \mathrm{min}$ two minutes after. If oversedation occurs, flumazenil, a specific benzodiazepine antagonist is given. However, flumazenil can induce withdrawal and seizure in patients treated with long-term midazolam therapy. The initial dose is usually 250 $500 \mu \mathrm{g}$ (Veaudor et al., 2017).

Propofol (2.6 diisopropylphenyl) is an emulsion formulation used for anesthesia induction and maintenance. Three random studies showed Propofol yielded adequate sedation with fast onset as well as resolution exceeding the benefits of midazolam or combination of diazepam and alfentanil. However, it is more expensive and requires skilled and experienced personnel in the management. The average sedation dose is $155 \mathrm{mg}$ (Jaggar and Haxby, 2002).

Combination of benzodiazepine and narcotics has been widely used. Combination of amnesia effects from benzodiazepine with analgesic and antitussive effects of narcotics are quite rational. Morphine is commonly used, but synthetic shortacting narcotics are more recommended. Combination of nalbuphine $(0.2 \mathrm{mg} / \mathrm{kg})$ and midazolam $(0.05 \mathrm{mg} / \mathrm{kg})$ generates a slightly higher level of $\mathrm{CO}_{2}$ than using only midazolam. Thus, sedation is recommended to be used in FOB if no contraindication is found, for instance in patients with severe COPD since it can stimulate hypoxia and $\mathrm{CO}_{2}$ retention (Veaudor et al., 2017; Jaggar and Haxby, 2002).

\subsection{Due to Local Anesthesia}

One of the FOB complications during premedication is the local anesthesia dose. Lignocaine (lidocaine) is the most frequently used local anesthesia and has better safety than cocaine, benzocaine and tetracaine with the same effectivity (Stolz et al., 2005). The administration is performed by three means: intratracheal injection, nebulizer and directly through a bronchoscope. Lignocaine administration through direct instillation into the endobronchial tree will be quickly absorbed and therefore is equal to the dosage level in the serum (Honeybourne et al., 2001).

It is important to be careful when dealing with lignocaine, particularly in liver metabolism, due to its toxic potential in patients with liver malignancy. Toxicity is rarely found, particularly with the dose of above $8 \mathrm{mg} / \mathrm{kg}$. The toxic side-effects include arrhythmia, seizure and cardiac suppression. In patients with heart and liver insufficiency where lignocaine metabolism might be impaired, the maximum dose given is $5 \mathrm{mg} / \mathrm{kg}$. Most studies recommend the maximum dose of $8.2 \mathrm{mg} / \mathrm{kg}$ equivalent to $29.3 \mathrm{ml}$ of $2 \%$ lignocaine in patients weighing $70 \mathrm{~kg}$ (Honeybourne et al., 2001; Stolz et al., 2007; Stolz et al., 2005).

\subsection{Due to Management during FOB}

\subsubsection{Hypoxia}

Several studies have reported hypoxia occurrence during FOB due to decreased arterial oxygen tension $\left(\mathrm{PaO}_{2}\right)$ of $\pm 2.5 \mathrm{kPa}$ during management. Hypoxia is more apparent if bronchial alveolar lavage (BAL) is conducted. The risk increases if there is quite a big volume of lavage fluid. Stridor that might occur during management will aggravate hypoxia (Honeybourne et al., 2001).

The mechanisms causing hypoxia include ventilation perfusion imbalance and secondary hypoventilation due to sedation. Ventilation perfusion imbalance occurrence depends on several factors. Natural reflex due to stimulation of subepithelial receptors by the bronchoscope can cause bronchoconstriction which leads to imbalance between ventilation and perfusion, big-dozed local anesthesia materials stimulating 
bronchoconstriction, partial airway obstruction due to the bronchoscope, suction and lavage fluid in alveoli as well as drug oversedation, especially opiates (McCain et al., 2001; Honeybourne et al., 2001).

Hypoxia can also occur in patients with pneumonia treated with FOB. This is due to respiratory tract mechanical occlusion affecting lobes that aggravate airflow. In non-pneumonia, collateral ventilation might prevent hypoxia mechanisms. Thus, the combination of reflex stimulation and ventilation-perfusion imbalance related to airway obstruction becomes the cause of most hypoxia during FOB (Kvale, 2002).

To avoid the risk accompanying hypoxia, particularly in heart arrhythmia, preparation is necessary for patients to be treated with FOB. Anemia correction should be conducted prior to FOB. Recommended safety limits of oxygen saturation $\left(\mathrm{SaO}_{2}\right)$ is $90 \%$ (during breathing in normal condition) equal to $\mathrm{PaO}_{2}$ of $8 \mathrm{kPa}$. If sedation is given before FOB (such as preoral diazepam), then monitoring with oximetry is necessary before FOB (Kvale, 2002).

Hypoxia might occur when FOB is finished. Oxygen supplementation after FOB is beneficial, particularly in patients with pulmonary function impairment (Honeybourne et al., 2001). The duration of oxygen administration in post-FOB partly depends on the type of sedation given previously. Long-term administration (1-2 hours) is required if patients are given oral diazepam compared to intravenous midazolam. Oxygen administration through nasal cannula should be performed with the flow of at least $21 /$ minute. Besides offering safety, oxygen administration also increases retention. Therefore, it can be used for patients at high risk of $\mathrm{CO}_{2}$ retention, $\mathrm{CO}_{2}$ monitoring and oxygen pressure (Jones and Driscoll, 2011).

\subsubsection{Heart Arrythmia}

The incidence of heart arrhythmia during FOB has been reported despite its low rates, i.e. $4-11 \%$. The risk of arrhythmia usually occurs when the bronchoscope passes the vocal cords (Honeybourne et al., 2001). A study of 70 patients during FOB reported major heart arrhythmia occurrence in 8 patients $(11 \%)$. Various heart arrhythmia that might occur are multifocal atrial tachycardia, atrial flutter and fibrillation, paroxysmal supraventricular tachycardia, atrial and ventricular premature complexes, right and left bundle branch blocks, AV nodal block type Wenckebach, and complete AV block (Mehta et al., 1999). Most of the disorders are related to hypoxia (P02 $<60 \mathrm{~mm} \mathrm{Hg}$ ), complex cellular dysfunction of severe acute hypoxia affecting metabolism and due to $\mathrm{PH}$ changes related to the changes of calcium, magnesium and katekolamin level in the circulation during FOB (Hassan et al., 2005).

Several researchers recommend ECG monitoring during FOB in patients with the abnormalities of 12 lead ECG and preoperative hypoxia, while routine heart monitoring is not recommended (Dunagan et al., 1998). Other researchers argued that ECG is only required in unstable angina (Honeybourne et al., 2001; Hassan et al., 2005). FOB is a safe procedure with low complication and mortality rates, i.e. 0.08 $1.7 \%$ and $0.01-0.1 \%$ respectively. The risk of FOB is reduced if conducted at least 4-6 weeks after myocardial infarction (Matot et al., 1999; Hassan et al., 2005).

$\mathrm{PaO}_{2}$ should be measured before FOB. If it is potential for $\mathrm{PaO}_{2}$ decrease to occur by $20 \mathrm{mmHg}$ or in patients with $\mathrm{PaO}_{2}$ of $\leq 70 \mathrm{mmHg}$, then oxygen administration is required to achieve the saturation of at least $90 \%$ to reduce the significant risk of arrhythmia during the procedure and recovery period. This way, the incidence of heart rhythm disorder during FOB can be reduced from $10 \%$ to $1 \%$ (Honeybourne et al., 2001).

\subsubsection{Bleeding}

Bleeding is one of the complications that occur during FOB. Significant $(>50 \mathrm{ml}$ ) occurred in 1.6$4.4 \%$ patients with diffuse pulmonary diseases treated with transbronchial biopsy. Several patients are at risk of bleeding, including patients with uremia, immunosuppression, pulmonary hypertension, liver disease, bleeding impairment or thrombocytopenia. FOB management in patients with superior vena cava obstruction (SVCO) requires special attention due to increased risk of bleeding (Honeybourne et al., 2001).

A study showed that FOB with BAL is quite safe and successful despite thrombocytopenia patients. Complications only occurred in 7 out of $58(12 \%)$ patients with thrombocyte counts of less than $100,000 / \mathrm{ml}$. Bleeding intensity is not well-correlated with thrombocyte counts or uremia level. However, other studies showed that FOB and BAL in patients with thrombocytopenia is only conducted after prophylaxis transfusion due to the caution towards bleeding complication. In general, thrombocyte transfusion is only performed if the amount is $>$ 
20,000/ml. Nevertheless, routine examination of coagulation physiology prior to FOB is not recommended (Weiss et al., 1993; Balfour-lyn and Spencer, 2002).

In patients at bleeding risk, for instance those with abnormal liver function test, in several rare cases requiring continuous anticoagulant administration, international normalized ratio (INR) should be reduced to $<2.5$ and heparin can be started. If biopsy is performed, oral anticoagulant medication should be stopped at least three days before FOB or substituted with low-dosed vitamin $\mathrm{K}$. If persistent bleeding occurs, patients are laid sideways on the bleeding side. The administration of lidocaine instillation and adrenaline solution of $1: 10,000$ can be taken into consideration (Honeybourne et al., 2001).

\subsubsection{Pneumothorax}

Pneumothorax rarely occurs after FOB. Most pneumothorax cases occur during drainage in transbronchial biopsy (3.5\%). Pneumothorax was reported to occur in $14 \%$ of patients with mechanical ventilation treated with transbronchial biopsy. In patients with diffuse pulmonary disease, pneumothorax incidence was reported to be $3 \%$ after transbronchial biopsy without previous fluoroscopy screening (Veaudor et al., 2017).

Symptoms and signs of pneumothorax might appear late after transbronchial biopsy. However, it is rare to discover pneumothorax one hour after transbronchial biopsy. Thus, it is recommended to perform thorax photo at least one hour after transbronchial biopsy to avoid the possibility of pneumothorax. Routine fluoroscopy is not recommended in transbronchial biopsy for patients with diffuse pulmonary diseases, but recommended for those with localized pulmonary lesions. Patients treated with transbronchial biopsy require spoken and written suggestions on pneumothorax possibility after discharge from the hospital (Veaudor et al., 2017).

\subsubsection{Infection}

Fever rarely occurs after FOB without lavage at the rate of $1.2 \%$. When lavage is included, it increases to $10-30 \%$ as correlated with the volume of lavage fluid used. The mechanism of fever after FOB remains unclear. It is presumably due to transient bacteremia, particularly in patients who are immunocompromised. Another presumption is that BAL incudes cytokines in alveolar macrophage cells. Significant increases were reported in IL-1b,
Il-6 and tumor necrosis factor- $\alpha$ (Honeybourne et al., 2001; Schnabel et al., 2015).

Antibiotic prophylaxis is not recommended unless for patients with asplenia, prosthetic heart valve or previous endocarditis history (Honeybourne et al., 2001). In several patients with heart structural disorder, an invasive medical procedure might trigger infectious endocarditis. The American Heart Association recommends routine endocarditis prophylaxis administration for invasive managements at high risk of bacteremia, such as dental care, catheterization and rigid bronchoscopy. FOB with or without biopsy is not included since the risk of bacteremia is low. A number of experts only recommend it for high-risk cardiac patients presumed to have respiratory tract infection (Schnabel et al., 2015).

\section{FOB PROCEDURE IN SPECIAL CONDITIONS}

\subsection{After Myocardial Infarction}

There are significant hemodynamic changes during FOB, including heart rate, mean arterial pressure and cardiac index. These changes are usually adjustable in patients with normal cardiovascular functions. Meanwhile, in patients with a previous hypertension history, coronary heart diseases or elderly, particularly those above 60 with pulmonary disease, there is adjustment failure leading to ischemia or myocardial infarction during FOB (Honeybourne et al., 2001; Kreider and Lipson, 2003). Hypoxia problems during FOB might contribute to ischemia occurrence, but cardiovascular stress factors, particularly hypertension and old age, also contribute to it (Hassan et al., 2005).

Arrythmia and increased risk of hypoxia requires special attention if performed in high-risk patients, especially of myocardial infarction. A retrospective study conducted on 20 patients undergoing FOB of averagely 12 days after acute myocardial infarction proved the safety of this therapy, although prior preparations are required, including continuous oxygen administration, ECG monitoring and adequate sedation administration to minimize tachycardia and hypertension incidence (Matot et al., 1999; Honeybourne et al., 2001). 


\subsection{Asthma and COPD}

The prevalence of COPD globally increases with approximately one out of 20 individuals suffering from COPD and every 8 patients' hospitalization triggers COPD exacerbation. Therefore, FOB procedure in patients with $\mathrm{COPD}$ also requires special attention. Patients with COPD tend to be treated with FOB since they have the history of cigarette smoke exposure leading to the high risk of malignancy (Stolz et al., 2007). Patients' COPD should be measured using a spirometer. If the COPD is categorized as severe (predicted FEV1 of $<40 \%$ and/or $\mathrm{SaO}_{2}$ of $<93 \%$ ), blood gas analysis measurement is then necessary (Honeybourne et al., 2001; Hattotuwa et al., 2002). In general, bronchospasm occurrence during FOB is rare with the percentage of only $0.02 \%$. However, a study conducted on 216 patients with asthma reported $8 \%$ of laryngospasm or bronchospasm incidence during FOB. Lignocaine might stimulate bronchoconstriction in patients with asthma and this can be prevented with atropine premedication. The decrease of FEV1 or forced vital capacity is higher in patients with asthma after BAL and bronchial biopsy (Honeybourne et al., 2001; Chiu et al., 2011).

In patients with asthma, there is excessive sensitivity compared to normal individuals. Various studies showed irritation stimulation or rapid acting receptors in the airway causing reflex bronchonconstriction in the vagal efferent pathway. Laryngospasm occurs due to vagal reflexes when the bronchoscope passes the vocal cords. Therefore, FOB is performed in patients with asthma in a relaxed state with bronchodilation administration (Sahn and Scoggin, 1976; Cowl et al., 2000).

FOB is safer in patients with COPD compared to those with asthma due to the low rate of hyper responsive bronchial mucosa. A study reported that short-acting agonists through inhalation give no benefit for patients with COPD. Thus, routine administration of short-acting agonist inhalation is not recommended as FOB premedication in COPD patients (Stolz et al., 2007).

On the contrary, the use of short-acting agonists is reported to prevent bronchoconstriction effects and FEV1 decrease in patients with asthma which increases the safety. The use of inhaled bronchodilator showed the decrease of changes in lung volume, the incidence of wheezing and oxygen desaturation. Therefore, agonist administration (through inhalation or a nebulizer) is highly recommended for patients with asthma prior to FOB, unless there are contraindications (Honeybourne et al., 2001; Stolz et al., 2007).

Sedation administration in patients with COPD is beneficial for suppressing coughing during FOB (Stolz et al., 2007). Midazolam has been the choice of medication and is used in $85 \%$ of all cases due to its short working duration and fast onset. Hydrocodone is a codeine derivative with a molecular structure similar to hydromorphone and has been widely accepted as a cough therapy. This drug has a bigger antitussive effect than codeine, but less than morphine. It is often used long term due to its minimum effect on the central nervous system and gastrointestinal tract compared to morphine. The combination of the two is often used to suppress coughing during FOB (Stolz et al., 2007). However, intravenous sedation has high potential to increase the risk of complication since it might increase arterial $\mathrm{CO}_{2}$ levels. Thus, the use of Pulse oximetry is highly recommended during FOB, as well as oxygen administration especially in patients with high risk or oxygen saturation of under 91\% (Jones and Driscoll, 2011).

\subsection{Old Age and Children}

Atelectasis is the primary indication for FOB in children, followed by stridor, immunocompromise, severe asthma, bronchiectasis and persistent wheezing. The procedures conducted are quite wide, including endobronchial biopsy, transbronchial biopsy, selective bronchography, laser therapy and dilatation of tissue damage, tracheal stenosis, tracheoesophageal fistula occlusion and bronchopleural as well as stabilization of airways with a stent (Efrati et al., 2007). The primary contraindications of FOB in children are severe hypoxia, uncontrolled bleeding diathesis, heart failure or severe pulmonary hypertension. The side-effects are rare and usually temporary. Complications usually occur in infants weighing $<10 \mathrm{~kg}$ (Bush, 2003).

One of the FOB complications in children requiring attention is bronchoscope size. If the size is too big, it might cause significant hypoxia and hypercarbia. The common size is $4.9 \mathrm{~mm}$ in children aged 7-8, $6 \mathrm{~mm}$ in adults and $2.8 \mathrm{~mm}$ in infants. Blood gas analysis should be conducted prior to the procedure. Monitoring should be performed, including saturation, blood pressure (ideally continuous and invasive) and the use of capnography is recommended (Balfour-lyn and Spencer, 2002). Premedication is also an important factor since $\mathrm{FOB}$ in children requires sedation. The ASA (1999) recommended infants 
aged $<1$ not to be given breast milk a maximum of 4 hours before FOB, while for those aged $>1$, food and milk should be given a maximum of 6 hours prior to FOB (Jaggar and Haxby, 2002).

Hypoxia is the biggest risk in FOB. In children, it is associated with laryngospasm, bronchospasm or excessive coughing, but the most common cause is partial airway obstruction by a bronchoscope and airway depression by sedation (Oliveira et al., 2002). The administration of intravenous sedation with midazolam and topical lidocaine in the upper airway might aggravate hypoventilation and hypoxia. Oxygen desaturation has been reported to occur more frequently in children of a younger age than those who are older age. The biggest decrease of oxygen saturation is mainly in younger patients aged 6-12, especially those with asthma, bronchopulmonary dysplasia, bronchial hyperactivity or recurrent wheezy bronchitis. $\beta 2$ agonist nebulizer administration prior to $\mathrm{FOB}$ in children with asthma and recurrent wheezing might reduce the risks (de Blic et al., 2002; Marchac and Scheinmann, 2002).

The risk of FOB complications potentially occurs in old age due to increased risk of acute myocardial infarction (IMA) and arrhythmia. Drugs metabolized in the heart, such as lignocaine and midazolam, show less efficiency compared to in young age groups and they can increase the risk of intoxication. However, several studies show no increased incidence of complications during $\mathrm{FOB}$ in the elderly (Honeybourne et al., 2001).

\section{FOB IN SPECIAL CONDITIONS}

\subsection{Intensive Care Unit (ICU) and Increased ICP}

FOB is used in ICUs with wide indication of diagnostics and therapy. FOB is often used for investigating and improving collapsed lobes that cannot be repaired using physiotherapy, getting rid of bronchus secretion causing major airway obstruction and infection predisposition, collecting strange objects in the airway and lavage or brushing microbiological samples in patients with pneumonia (Honeybourne et al., 2001).

Critical patients are the group at high risk for FOB since they often have hypoxia, electrolyte imbalance, clotting disorders and arrhythmia. Thus, the state of activated partial thromboplastin time (APPT) elongation, decreased fibrinogen titer or thrombocytopenia endangers biopsy management.
Physiology monitoring tools including ECG, continuous intra-arterial blood pressure and pulse oximetry can increase safety. It is quite important to monitor increased intracranial pressure in patients with head injuries since it is associated with $\mathrm{CO}_{2}$ retention. Anesthesia administration including effective neuromuscular blockade is required in patients with head injuries to be treated with FOB. Preoxygenation is necessary to acquire an oxygen concentration of $100 \%$ (Honeybourne et al., 2001).

The comparison between the inner diameter of the tracheal tube and its outer diameter should be taken into consideration. A bronchoscope in patients without intubation will take up only $10-15 \%$ of the overall tracheal flat latitude. In contrast, a bronchoscope of $5.7 \mathrm{~mm}$ will take up $40 \%$ of ETT with a diameter of $9 \mathrm{~mm}$ and $66 \%$ of the tracheal tube. Failure to recognize this leads to inadequate ventilation and bronchoscope damage. Tracheostomy also causes bronchoscope damage, particularly during the pull-out since the end corner of tracheostomy might wound the outer bronchoscope. Lubrication is important in bronchoscopy (Honeybourne et al., 2001).

Patients' clinical status can determine the type and level of sedation. Unstable hypoxia with acute respiratory distress syndrome might require deep sedation, analgesics or muscle relaxant to maintain oxygenation and prevent patients from resisting the ventilator. Synthetic narcotics such as alfentanil or fentanyl will suppress coughing and maintain the depth of analgesics. Sedation can be induced. Some patients might only need mild sedation for comfort. In several FOB cases, local anesthesia is given with lignocaine through a bronchoscope. The dose of lignocaine is usually smaller than in patients without intubation (Honeybourne et al., 2001; Chandra et al., 2011).

\subsection{Pregnancy}

Increased estrogen levels during pregnancy lead to several changes in upper airway mucosa, such as hyperemia, glandular hyperactivity, increased phagocytic activities and increased content of mucopolisacaridos mucosa. These changes lead to the conditions known as rhinitis and gingivitis. Increased mucosal edema causes bleeding tendency which leads to bronchoscope insertion problems (Bahhady and Ernst, 2004).

Increased gastroesophageal reflux prevalence during pregnancy includes mechanical and intrinsic factors reducing lower esophageal sphincter movement. Thus, it theoretically increases the risk of 
aspiration during sedation and FOB. Uterus enlargement at a pregnancy age of more than 20 weeks might suppress inferior vena cava decreasing cardiac preload and causing a condition, namely supine hypotensive syndrome which occurs in an average of $8 \%$ of all pregnancies. This syndrome is characterized by the symptoms and signs of reduced cardiac output and decreased mean arterial pressure to $15 \mathrm{mmHg}$. A patient with sedation might not be able to show the response of alert signs required earlier. Therefore, FOB should be performed with patients in the left lateral tilt position by putting a prop on the right side of the body (Bahhady and Ernst, 2004).

In general, it is recommended to avoid FOB during pregnancy due to its relation with procedure risks and sedative relation to the mother and the baby. However, there are several situations in which this procedure cannot be delayed for diagnostics and therapy. Emergence indications for FOB include airway liberation in the case of upper airway obstruction due to subglottic critical stenosis. The risk in fetus can be minimized by fetus monitoring, adequate oxygenation in the mother and avoiding drugs triggering hypotension. In a non-emergency state, undergoing FOB is an individual decision and highly depends on the mother's health status and pregnancy age. If possible, it is better to wait for labor, especially if the pregnancy age is above 28 weeks. Diagnosis establishment therapy for pulmonary as well as airway diseases, including endobronchial ultrasound, CT fluoroscopy and virtual bronchoscopy might be required in combination with FOB to reduce the risk in the mother and baby (Bahhady and Ernst, 2004).

Fetuses are highly sensitive to hypoxia and hypotension in the mother. Hypoxia in the mother might be due to medications, vagal reflexes stimulating bronchospasm and pulmonary aspiration. There is no official recommendation to conduct baby's heart monitoring during FOB. Many case series reported that baby's heart monitoring is only indicated for high-risk pregnant mothers or if conducted in the third semester (Bahhady and Ernst, 2004).

\section{SUMMARY}

FOB is a safe procedure with few complications and low mortality rates, ranging between $0.5-6.8 \%$ depending on the type of management. The complications occur during premedication (anticholinergic and local anesthesia) and sedation, during FOB (hypoxia, arrythmia and bleeding) and FOB with special conditions, i.e. after myocardial infarction, asthma, COPD, the elderly, children, ICU, increased intracranial pressure and pregnancy.

\section{REFERENCES}

BAHHADY, I. J. \& ERNST, A. 2004. Risks of and recommendations for flexible bronchoscopy in pregnancy: a review. Chest, 126, 1974-81.

BALFOUR-LYN， I. \& SPENCER, H. 2002. Bronchoscopy-how and when. Paediatric respiratory reviews, 3, 255-264.

BUSH, A. 2003. Bronchoscopy in paediatric intensive care. Paediatric respiratory reviews, 4, 67-73.

CHANDRA, A., BANAVALIKER, J. N. \& AGARWAL, M. K. 2011. Fibreoptic bronchoscopy without sedation: Is transcricoid injection better than the "spray as you go" technique? Indian J Anaesth, 55, 483-7.

CHIU, P. C., CHENG, K. I., TSENG, K. Y., SHIH, C. K. \& CHEN, M. K. 2011. Fibreoptic bronchoscopy to facilitate ProSeal laryngeal mask airway insertion in a patient with ankylosing spondylitis. Anaesthesia, 66, 138-9.

COWL, C. T., PRAKASH, U. B. \& KRUGER, B. R. 2000. The role of anticholinergics in bronchoscopy. A randomized clinical trial. Chest, 118, 188-92.

DE BLIC, J., MARCHAC, V. \& SCHEINMANN, P. 2002. Complications of flexible bronchoscopy in children: prospective study of 1,328 procedures. Eur Respir J, 20, 1271-6.

DUNAGAN, HENRY, L., BURKE, SUZANNE, L., AQUINO, JR., R. C. \& NORMAN, E. 1998. Fiberoptic bronchoscopy in coronary care unit patients: indications, safety, and clinical implications. Chest, 114, 1660-1667.

EFRATI, O., GONIK, U., MODAN-MOSES, D., BIELORAI, B., BARAK, A., VARDI, A., PARET, G., MISHALY, D. \& TOREN, A. 2007. The role of flexible fibreoptic bronchoscopy in evaluation of pulmonary diseases in children with congenital cardiac disease. Cardiol Young, 17, 140-4.

HASSAN, G., QURESHI, W., KHAN, G. \& ASMI, R. 2005. Cardiovascular consequences of fiberoptic bronchoscopy. JK science, 7, 1-2.

HATTOTUWA, K., GAMBLE, E. A., O'SHAUGHNESSY, T., JEFFERY, P. K. \& BARNES, N. C. 2002. Safety of bronchoscopy, biopsy, and BAL in research patients with COPD. Chest, 122, 1909-12.

HONEYBOURNE, D., BABB, J., BOWIE, P., BREWIN, A., FRAISE, A., GARRARD, C., HARVEY, J. \& LEWIS, R. 2001. British Thoracic Society guidelines on diagnostic flexible bronchoscopy. Thorax, 56, (suppl I) i1-i21. 
JAGGAR, S. I. \& HAXBY, E. 2002. Bronchoscopy in a 12-month-old boy being treated for leukaemia. Paediatr Respir Rev, 3, 356, 359.

JONES, A. M. \& DRISCOLL, R. 2011. Do all patients require supplemental oxygen during flexible bronchoscopy? Chest, 119, 1906-1909.

KREIDER, M. E. \& LIPSON, D. A. 2003. Bronchoscopy for atelectasis in the ICU: a case report and review of the literature. Chest, 124, 344-50.

KVALE, P. A. 2002. Prevention and management of hypoxemia during fiberoptic bronchoscopy. Chest, 121, 1021-2.

MARCHAC, J. D. \& SCHEINMANN 2002. Complications of flexible bronchoscopy in children: prospective study of 1,328 procedures. Eur Respir J, 20, 1271-1276.

MATOT, I., DRENGER, B., GLANTZ, L. \& KRAMER, M. R. 1999. Coronary spasm during outpatient fiberoptic laser bronchoscopy. Chest, 115, 1744-6.

MCCAIN, T. W., DUNAGAN, D. P., ADAIR, N. E. \& CHIN, R., JR. 2001. Prospective randomized trial comparing oxygen administration during nasal flexible bronchoscopy : oral vs nasal delivery. Chest, 120, 1671-4.

MEHTA, D. A., RAFANAN, A. L., BULKLEY, R., WALSH, M. \& GLENN, E. 1999. Coronary spasm and cardiac arrest from carcinoid crisis during laser bronchoscopy. Chest, 115, 598-600.

OLIVEIRA, C. F., ALMEIDA, J. F., TROSTER, E. J. \& VAZ, F. A. 2002. Case reports: complications of tracheobronchial foreign body aspiration in children: report of 5 cases and review of the literature. Rev. Hosp. Clín. Fac. Med. S. Paulo, 57, 108-111.

ROJAS 2006. Bronchoscopy in children in south america.

SAHN, S. A. \& SCOGGIN, C. 1976. Fiberoptic bronchoscopy in bronchial asthma. A word of caution. Chest, 69, 39-42.

SCHNABEL, R. M., VAN DER VELDEN, K., OSINSKI, A., ROHDE, G., ROEKAERTS, P. M. \& BERGMANS, D. C. 2015. Clinical course and complications following diagnostic bronchoalveolar lavage in critically ill mechanically ventilated patients. BMC Pulm Med, 15, 107.

STOLZ, D., CHHAJED, P. N., LEUPPI, J., PFLIMLIN, E. \& TAMM, M. 2005. Nebulized lidocaine for flexible bronchoscopy: a randomized, double-blind, placebo-controlled trial. Chest, 128, 1756-60.

STOLZ, D., POLLAK, V., CHHAJED, P. N., GYSIN, C., PFLIMLIN, E. \& TAMM, M. 2007. A randomized, placebo-controlled trial of bronchodilators for bronchoscopy in patients with COPD. Chest, 131, 765-772.

VEAUDOR, M., COURAUD, S., CHAN, S., CHOUN, C., KEO, P., AVRILlON, V., SOUQUET, P. J. \& NY, C. 2017. Implementing flexible bronchoscopy in least developed countries according to international guidelines is feasible and sustainable: example from Phnom-Penh, Cambodia. BMC Pulm Med, 17, 10.

WEISS, S. M., HERT, R. C., GIANOLA, F. J., CLARK, J. G. \& CRAWFORD, S. W. 1993. Complications of fiberoptic bronchoscopy in thrombocytopenic patients. Chest, 104, 1025-8. 